INTERNATIONAL MONETARY FUND

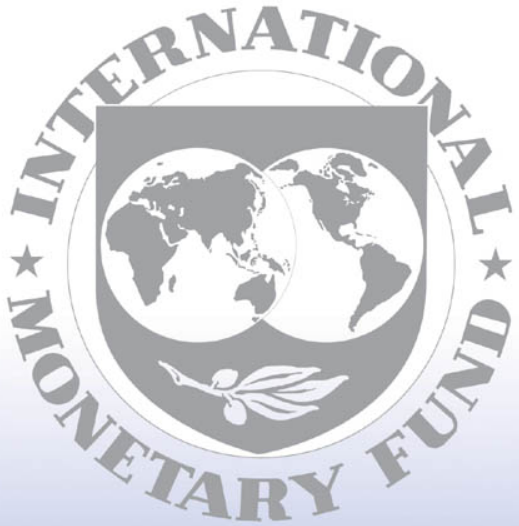

Staff

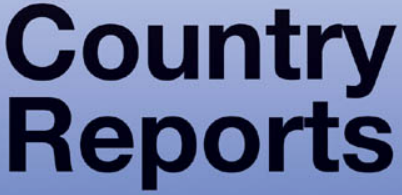




\title{
Czech Republic: Report on the Observance of Standards and Codes-Fiscal Transparency, Banking Supervision, Insurance Regulation, Securities Regulation, Payment Systems, and Monetary and Financial Policy Transparency-Updates
}

\begin{abstract}
These updates to the Report on the Observance of Standards and Codes for the Czech Republic were prepared by a staff team of the International Monetary Fund as background documentation for the periodic consultation with the member country. They are based on the information available at the time they were completed on July 11, 2002. The views expressed in these documents are those of the staff team and do not necessarily reflect the views of the government of the Czech Republic or the Executive Board of the IMF.

The policy of publication of staff reports and other documents by the $\mathrm{MF}$ allows for the deletion of market-sensitive information.
\end{abstract}

To assist the IMF in evaluating the publication policy, reader comments are invited and may be sent by e-mail to Publicationpolicy@imf.org.

Copies of this report are available to the public from International Monetary Fund - Publication Services $70019^{\text {th }}$ Street, N.W. - Washington, D.C. 20431

Telephone: (202) 623-7430 - Telefax: (202) 623-7201

E-mail: publications@imf.org Internet: http://wmw.imf.org

Price: $\$ 15.00$ a copy

\section{International Monetary Fund Washington, D.C.}




\section{Report on the Observance of Standards and Codes CzeCH REPUblic-FisCal Transparency: AN UPDATE JULY 2002}

This note provides a factual report on developments in fiscal transparency since the September 1999 "Experimental Report on the Observance of Standards and Codes-Czech Republic" (EBS/99/158, 9/1/99) and the June 2000 and June 200I updates. For a full description of institutions and practices, it should be read in conjunction with the original report. ${ }^{1}$

The 1999 report on fiscal transparency concluded that fiscal management has become increasingly transparent, a conclusion confirmed in the 2000 and 2001 updates. At the same time, the assessments identified several shortcomings from international best practice, relating in particular to the management of spending outside of the State Budget and the treatment of quasi fiscal spending and fiscal risk.

\section{A. Clarity of Roles and Responsibilities}

A significant share of public spending takes place outside of the State Budget (about 40 percent in 2001 and a projected 44 percent in 2002). It has increased in recent years, partly as a result of the creation of new extra-budgetary funds (EBFs), notably the Transport and Infrastructure Fund and the Housing Fund. In 2001-02, the establishment of new regional administrations also contributed to this trend. This raises at least two issues:

- Transparency: While the budgets of the principal EBFs are also approved by parliament, public focus is on the State Budget. ${ }^{2}$ Monthly data are released for the operations of the State Budget, but data on the operations of the EBFs and local governments are published only annually. ${ }^{3}$

- Accountability: State Budget spending is subject to detailed rules, which were recently atmended and tightened. ${ }^{4}$ In the case of EBFs, however, the nules can differ, depending on

${ }^{1}$ The reports are available on the IMF website http://www.imf.org/external/np/rosc/rosc.asp.

${ }^{2}$ The fiscal targets of the government's program have also been formulated in terms of the State Budget deficit in recent years.

${ }^{3}$ From 2003 , the Central Statistical Office intends to compile and publish quarterly general government accounts according to the EU's ESA95 standard.

${ }^{4}$ See the June 2000 and June 2001 updates for a full description of the change in the State Budget rules. 
the specific law under which they were created. In the case of the National Property Fund (NPF) and the Czech Land Fund, accounting rules are quite different. The regions and municipalities are subject to so-called "small budgetary rules," which are less stringent than those applied to State Budget operations.

The establishment in 2001 of 14 new regional governments and administrations poses specific issues. To the extent that the activities of the regions are financed from the State Budget, these are at least implicitly subject to the same State Budget rules. In 2001, the year of their establishment, this was the case, as their revenue consisted fully of transfers from the State Budget. But from 2002, they were granted revenue sources of their own (ear-marked shares of certain centrally levied taxes) and their operations are therefore subject to the "small budgetary rules" for self-administrative regional bodies.

A June 2002 amendment of the Act on Municipalities and the Act on Regions eliminated the existing limits on borrowing and the extension of guarantees, allowing both municipalities and regions to run a deficit, provided they can generate the necessary financing. The new law states explicitly that the State Budget is not liable for the debt of the municipalities and regions. The 77 district offices, which in the past played a linking role between the central government and the municipalities, are slated to be closed by end-2002. Hence, from 2003, the accounting and auditing function of the district offices vis-à-vis municipalities will need to be replaced. To this end, a new law on the audit of regional and municipal government is under preparation.

The Czech Republic continues to lack a comprehensive perspective on fiscal risks. While the extension of government guarantees has dropped sharply (each guarantee requires separate parliamentary approval since 2001), other forms of contingent liabilities are still not fully captured, for example those resulting from the operations of the NPF or the Czech Consolidation Agency. ${ }^{5}$ Moreover, there is no requirement to quantify tax expenditures (which are likely to be substantial under various tax holiday provisions in the investment incentive program, for example). And looking ahead, there is a risk that current commitments entailing significant future liabilities (for example, the decision to transfer road construction, operation, and maintenance to a private sector company-against large annual "user fees" paid by the government) may not be fully integrated in medium-term fiscal decision-making.

\section{B. Independent Assurances of Integrity}

The Supreme Audit Office (SAO) continues to perform independent and high-quality audits. ${ }^{6}$ Its responsibility extends beyond the State Budget and covers the EBFs as well, including the

\footnotetext{
${ }^{5}$ However, the NPF is required to create reserves to guard against possible calls on guarantees.
}

${ }^{6}$ See EBS/99/158, 9/1/99, Section III, paragraph 19 and the SAO's website (www.nku.cz). 
NFP (although, because of their recent introduction, neither the Transport and Infrastructure Fund nor the Housing Fund has yet been audited). However, its mandate is limited to statelevel institutions: the auditing of municipal budgets is the responsibility of the 77 district offices.

One of the SAO's key reports is an evaluation of the State Final Accounts, the annual final budgetary accounts prepared by the ministry of finance $(\mathrm{MoF})$. The full reports of the SAO are provided to the Chamber of Deputies, the Senate, the government of the Czech Republic, the Czech National Bank, and upon request to ministries concerned. The full reports are included jn the quarterly SAO Bulletin.

The SAO's current main focus remains the conduct of compliance audits, but it is moving toward standard financial audits ${ }^{7}$, and increasingly conducting value-for-money (i.e., performance) audits, for example in area of transportation (railway corridors, the road system). Over time, the SAO intends to devote an equal amount of resources to financial audits and to performance audits, although as in other countries it will take some time to build the staff capacity to conduct performance audits.

\section{Staff Commentary}

The Czech Republic meets many of the objectives set out in the Code of Good Practices on Fiscal Transparency. Through its regular publications, the $\mathrm{MoF}$ has maintained a high standard of public availability of information on government finances and the introduction of new budgetary rules in 2001 has contributed to an improvement in the accountability of public finances. However, these achievements are generally limited to the state budget operations. The operations of the EBFs and local governments, accounting for a rising share of public spending, are subject to different rules and regulations, which can pose problems for transparency and accountability. Moreover, fiscal reporting does not reflect fully the potential for future fiscal risks stemming, for example, from contingent liabilities outside of the State Budget, nor is the cost of tax concessions systematically reported. The Supreme Audit Office continues to perform independent and high-quality audits at the state level, and its intention to increase the number of performance audits is welcome.

${ }^{7}$ Currently supported by a "twinning" project with the German Bundesrechnungshof. 


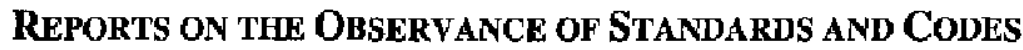 CZECH REPUBLIC-FinanCIAL SECTOR MOdULES: INFORMATIONAL UPDATES JuLY 2002}

This note provides factual updates on developments with respect to the abservance of international standards in the financial sector since the publication of the June 2001 report entitled "Czech Republic-Financial System Stability Assessment" (SM/01/189, 6/27/01). For a full description of institutions and practices, it should be read in conjunction with the original report.

The 2001 report noted that the Czech authorities have placed high priority on implementing and observing the international standards relevant for financial stability. This effort had been spurred by the prospects of EU accession and the ongoing harmonization of the legal and institutional framework with that of the EU. Consequently, a massive effort was underway to enhance the regulatory, supervisory, and transparency framework and strengthen the market infrastructure. At the same time, the report emphasized that further progress was needed in a number of areas. The remainder of this update discusses the progress made over the past year against the recommendations made in the original assessment.

\section{Core Principles (CP)}

\section{A. Basel Core Principles of Banking Supervision}

The original assessment found that the Czech National Bank (CNB) had strengthened the supervisory framework in recent years, tightening requirements for licensing, provisioning, and disclosure. It also noted that the supervisory staff was gaining in professionalism, and its awareness and understanding of international supervisory standards, policies, and practices was found to be very high. At the same time, the original assessment noted that the supporting legal system remained in transition, with significant weaknesses, for example, in laws governing debtor-creditor relations. Particularly in the case of problem banks, the large array of laws, inefficiencies in the judicial process, and cumbersome administrative requirements, were found to impede effective and timely supervisory enforcement. Also, supervisory skills to assess market risk, audit computer-based systems, and evaluate risk management systems, were found to be low.

The adoption of new legislation over the past year, in particular the amendments of the Act on the CNB and the Act on Banks, aim at a significant improvement in the legal framework. The following developments took place over the past year in the areas raised by the summary of main findings in the original report (Table 9):

${ }^{1}$ The report is available on the IMF website http://www.imf.org/external/np/rosc/rosc.asp. 


\section{CP 1 (Objectives, Autonomy, Powers, and Resources)}

- The CNB adopted a Medium-term Concept Document for bank supervision and bank regulation, which aims at establishing a formal system of appraising supervisory performance.

- Two further amendments of the Act on the Czech National Bank, effective January 1 and May 1, 2002, aim at fully harmonising the law with European law and the statutes of the European Central Bank (ECB), ensuring the full independence of the $\mathrm{CNB}$, including in terms of budgetary resources required for effective and timely supervision.

- Supervisory decision-making does allow for the inclusion of qualitative judgements; however, it carries the risk of exposing the CNB to legal action.

- No progress has been made in strengthening the legal protection of supervisors.

- Progress toward risk-based supervision has continued. Establishing appropriate procedures to do so is among the priorities in the Medium-term Concept Document, and a new framework of internal rating is scheduled for 2003.

\section{CP 2-5 (Licensing and Structure)}

- The CNB has issued a new decree on licensing procedures, effective May 1, 2002, which includes new transparency requirements and aims at strengthening the identification of beneficial owners, based on the amendment of the Act on Banks.

- The amendment of the Act on Banks, and the new CNB decree on licensing procedures, now permit fit-and-proper tests below the Board level.

\section{CP 6-15 (Prudential Regulations and Requirements)}

- Strengthering the prudential framework relating to credit risk is among the priorities in the Medium-term Concept Document, and the CNB plans to issue several regulations in the course of 2002 to encourage better risk management among banks. At the same time, the CNB is strengthening its ability to assess market risk, including through value-at-risk methodologies.

- Using differential capital ratios based on individual banks' business and control risks is not possible under the Act on Banks.

- A CNB decree on anti-money laundering policies and procedures, aimed at strengthening "know-your-customer" requirements, is under preparation and should be implemented by end-2002. 


\section{CP 16-20 (Methods of Ongoing Supervision)}

- The amended Act on Banks has extended consolidated supervision to financial holding companies and mixed holding companies. Capital adequacy requirements and large exposure limits now apply to bank-led groups and financial holding companies, and the CNB can ask nonbank members of a financial group to submit regular information to the CNB.

\section{CP 21 (Information Requirements)}

- Effective January 1, 2002, an amendment of the Accounting Act in 2001, and the ministry of finance's $(\mathrm{MoF})$ implementing by-law, aim at making Czech accounting rules for financial instruments (securities, derivatives, financial placements of insurance companies) fully compatible with International Accounting Standards and European law. The new rules will be applied to produce financial statements of nonbank financial institutions (insurance companies, brokers, pension funds etc.), financial holding companies, and mixed holding companies.

\section{CP 22 (Formal Powers of Supervisors)}

- There have been no changes in the supervisors' powers for prompt corrective action since end-2000. However, the extension of consolidated supervision has strengthened the power of the CNB.

\section{B. International Association of Insurance Supervisors (IAIS) Core Principles of Insurance Regulation}

The original assessment found that the regulation and supervision of the Czech insurance sector had improved in recent years, with the adoption of a modern insurance law that is harmonized with EU legislation. However, the assessment concluded that the legal framework needed to be further strengthened in several important areas: corporate governance of insurance companies - and especially the requirements for the boards of the companies-were not deemed adequate; legislation in specific areas, including licensing, needed to be strengthened; the supervisory authority-the Office of Supervision, located within a department of the $\mathrm{MoF}$ - was found to lack sufficient legal and operational independence; and the transparency of the Office was found to be less than desirable, both as a result of strict confidentiality requirements and because of lack of adequate resources to discharge its primary responsibilities.

The following developments took place over the past year in the areas raised by the summary of main findings in the original report (Tables 11 and 12):

- There has been no change in the status of the Office of Supervision. However, an amendment of the Act on Insurance is under preparation, and one of the objectives is to strengthen the independence of the supervisor. 
- Corporate governance is governed by provisions of the Commercial Code, which have not changed over the past year.

- There have been no changes in the Office of Supervision's inspection procedures to encompass risk management and internal controls.

- There have been no changes in supervisory procedures for dealing with issues not specified in legislation, such as reinsurance arrangements, derivatives, and off-balance sheet items, as recommended by the original assessment. However, the Office of Supervision notes that the existing legal framework, and its implementing decree, fully cover these issues.

- The Office of Supervision has not established a consumer protection program, as recommended by the original assessment. However, the Office of Supervision notes that this is the responsibility of the Czech Insurance Association, which has a code of conduct.

- The number of inspections has risen sharply in 2001, reflecting an increase in staffing at the Office of Supervision. The Office disagrees with the view expressed in the original assessment calling for more staff training, pointing to numerous internal and external training seminars, consultations with other supervisors, and an ongoing twinning program funded by the EU.

\section{International Organization of Securities Commissions (IOSCO) Objectives and Principles of Securities Regulation}

The original assessment concluded that, broadly speaking, the laws and regulations of the Czech Republic give sufficient powers to the Czech Securities Commission (CSC) to permit effective regulations of the securities markets. However, the assessment noted that there were practical limitations to the capacity of the CSC to discharge its responsibilities, resulting primarily from a lack of adequate resources.

The following developments took place over the past year in the areas raised by the summary of main findings in the original report (Table 13):

- An amendment of the Securities Commission Act has been adopted by parliament and will become effective as soon as it is published. The amendment addresses a number of key issues raised in the original assessment, including: (i) the CSC will be empowered to issue secondary legislation; (ii) rating agencies, currently uncovered by the law, will in future be subject to licensing by the Trade Licensing Office--and approval by the CSC; (iii) the CSC will be empowered to impose forced administration (intervention) on brokers; currently it is limited to investment funds. But if the brokerage is part of a bank, then forced administration can be imposed only by the CNB; (iv) the new law clarifies the use of the Guarantee Fund, specifying that it can be used only to cover clients' funds, not other liabilities of the brokers; and (v) the new law clarifies that the SEC has the 
discretion, not the obligation, to impose sanctions under certain circumstances; (vi) the new law extends the brokerage houses' disclosure duty (on their financial situation, capital adequacy, etc); and (vii) in accordance with the relevant EU directive, the new law clarifies confidentiality rules and information dischosure rules for the CSC, and also specifies the CSC's mission and objectives.

- However, the financial independence of the CSC remains limited as it continues to be fully funded from the State Budget.

- Staff resources have not been increased over the past year. However, the budget for staff training was raised sharply.

\section{Core Principles for Systemically Important Payment Systems (CPSIPS)}

The original assessment concluded that the CNB's Clearing Center observes most of the applicable CPSIPS. The following developments took place over the past year in the areas raised by the summary of main findings in the original report (Table 15):

- The new Act on Payment Transfers, Electronic Money Transfers and Payment Systems (No. 124/2002 Coll.) was introduced in Aptil 2002. This Act will enter into force on January $1,2003$.

\section{Monetary policy ${ }^{2}$}

\section{Transparency}

The original assessment found that, overall, the institutional framework, the CNB's relationship with the government, agency responsibilities and operational procedures for the conduct of monetary policy, and monetary policy implementation in the Czech Republic, were highly transparent. It also identified a few areas in which existing practices could be further clarified and strengthened.

The following developments took place over the past year in the areas raised by the summary of main findings in the original report (Table 8):

- Since the amendment of the Constitution effective January 1, 2002, and the new amendment of the CNB Act that came into force on May 1, 2002, the primary objective of the CNB is to maintain price stability-modeled on that of the ECB.

${ }^{2}$ Against the IMF Code of Good Practices on Transparency in Monetary and Financial Policies. 
- The terms of government deposits at the central bank are specified in a service agreement with the $\mathrm{MoF}$, the details of which remain undisclosed. However, the $\mathrm{CNB}$ publishes its balance sheet every 10 days, in which interest payments on government deposits are separately shown.

- The CNB's responsibilities regarding the management of domestic and external public debt are defined in relevant legislation. But they are not systematically disclosed in the CNB's Annual Report and website.

- The CNB does not consult systematically with market participants and other interested parties on changes in monetary regulations. However, their comments are usually taken into account when introducing operational changes, especially in view of the convergence of the CNB's monetary instruments with those of the ECB.

- The amounts used of the CNB's automatic deposit and credit facilities are now disclosed daily on the CNB website.

- The amounts of the CNB's emergency financial are disclosed in its balance sheet under receivables from domestic banks (assets).

- The CNB's internal governance procedures, including rules to avoid conflicts of interest remain undisclosed.

\section{Banking supervision}

The original assessment found that in many respects, the CNB observes international good practices regarding the transparency of banking supervision. The CNB has full operational and financial independence on supervisory matters, and it pursues an open policy on supervisory policies and regulations. Banking supervisory policies, regulations, and developments are provided to the market and public in a comprehensible, accessible, and timely manner-using a variety of means to communicate with the public.

The following developments took place over the past year in the areas raised by the summary of main findings in the original report (Table 10):

- The scope and procedures for cooperation and information sharing between the $\mathrm{CNB}$, the $\mathrm{CSC}$, and the MoF is now available on the CNB's website.

- The CNB does not publicly disclose its internal procedures for conducting banking supervision, although the CNB periodically issues official statements clarifying various complex supervisory issues.

- The CNB has signed three memoranda of understanding (MoU) with foreign supervisory counterparts: in 1999 with the National Bank of Slovakia, and in 2001, with the Austrian $\mathrm{MoF}$, and in 2002 with the French Commission Bancaire. The second has been disclosed 
on the CNB's website, and it is the intention to disclose all MoUs after securing the consent of the partner regulators.

- The amendment of the Act on Banks provides a legal framework for the further development of cooperation with foreign supervisory authorities.

\section{Insurance regulation}

- No steps have been taken over the past to increase the transparency of the Office of Supervision.

\section{Securities regulation}

- Several steps have been taken to enhance the transparency of the stock market and prevent manipulation and unfair trading practices: (i) disclosure requirements have been further harmonized with EU directives; (ii) there has been increased cooperation and coordination between the CSC and the stock exchange; and (iii) brokerages and institutional investors are required to inform the CSC of all off-exchange trades, whether concluded on a brokerage's own account or on behalf of clients.

\section{Payments system oversight}

- The CNB has presented its procedures, policy and objectives through the Czech Banking Association, on its web pages, TV programs and in the press (in both newspapers and specialized magazines). A more detailed description is provided in the CNB's Annual Report. 